\title{
Multiagent imaging of inflammation and infection with radionuclides
}

\author{
Christopher J. Palestro • Andor W. J. M. Glaudemans • \\ Rudi A. J. O. Dierckx
}

Received: 7 June 2013/ Accepted: 13 November 2013/Published online: 23 November 2013

(C) Italian Association of Nuclear Medicine and Molecular Imaging 2013

\begin{abstract}
Molecular imaging with single photon- and positron-emitting tracers plays an important role in the evaluation of inflammation and infection. Although supplanted by labeled leukocyte imaging for most indications, gallium-67 remains useful for opportunistic infections, pulmonary inflammation and interstitial nephritis and, when $\left[{ }^{18} \mathrm{~F}\right] \mathrm{FDG}$ is not available, spinal infection and fever of unknown origin. In vitro labeled leukocyte imaging is the radionuclide procedure of choice for most infections in immunocompetent patients. When performed for musculoskeletal infection, complementary bone marrow imaging usually is necessary. Recent data suggest that dual time point imaging might be an alternative to marrow imaging. Several methods of labeling leukocytes in vivo, with agents including antigranulocyte antibodies and antibody fragments, peptides and cytokines, have been investigated, with
\end{abstract}

Color figures online at http://link.springer.com/article/10.1007/ s40336-013-0041-z.

\section{J. Palestro}

Department of Radiology, Hofstra North Shore-LIJ,

School of Medicine, Hempstead, NY, USA

\section{J. Palestro}

Division of Nuclear Medicine and Molecular Imaging, North

Shore-Long Island Jewish Health System, Manhasset, NY, USA

\section{J. Palestro ( $\square)$}

Division of Nuclear Medicine and Molecular Imaging, Long Island Jewish Medical Center, 270-05 76th Avenue, New Hyde Park, NY 11040, USA

e-mail: palestro@lij.edu

A. W. J. M. Glaudemans - R. A. J. O. Dierckx Department of Nuclear Medicine and Molecular Imaging, University of Groningen, University Medical Center Groningen, Groningen, The Netherlands variable results. These agents are not widely available and none of them are available in the USA. Radiolabeled antibiotics have been investigated as "infection-specific" tracers, but the results to date have been disappointing. Conversely, radiolabeled antimicrobial peptides do hold promise as infection-specific tracers. The use of positronemitting tracers for diagnosing inflammation and infection has generated considerable interest. $\left[{ }^{18} \mathrm{~F}\right] \mathrm{FDG}$ is useful in fever of unknown origin, spinal osteomyelitis, vasculitis and sarcoidosis. Other positron-emitting tracers that have been investigated include $\left[{ }^{18} \mathrm{~F}\right] \mathrm{FDG}$-labeled leukocytes, copper-64-labeled leukocytes, gallium-68 citrate and iodine-124 FIAU. Although radiolabeled tracers are used primarily for diagnosis, they also offer objective biomarkers for assessing response to therapeutic interventions in inflammatory diseases. They could also potentially be used to target cells and molecules with specific receptor expression for histological characterization, select patients for receptor-targeted therapy and predict response to treatment.

Keywords Gallium citrate - Labeled leukocytes . Biotin $\cdot$ Antimicrobial peptides $\cdot\left[{ }^{18} \mathrm{~F}\right] \mathrm{FDG} \cdot \mathrm{PET}$

\section{Introduction}

Despite significant advances in our understanding of microorganisms and the pathogenesis of inflammation and infection, infection remains a major cause of patient morbidity and mortality. Although signs and symptoms such as fever, pain, general malaise and abnormal laboratory results may suggest the presence of infection, the diagnosis can be elusive and imaging tests often are used for confirmation and localization. There are two principal 
categories of imaging tests: anatomical or morphological, and molecular. Anatomical imaging tests, such as radiographs, ultrasound and computed tomography (CT) reveal structural alterations in tissues and organs caused by microbial invasion and the inflammatory response of the host. Prototypical molecular imaging tests use agents such as gallium-68 citrate, labeled leukocytes and fluorine-18 fluorodeoxyglucose $\left(\left[{ }^{18} \mathrm{~F}\right] \mathrm{FDG}\right)$. These agents, which reflect the physiological changes that are part of the inflammatory process, are taken up directly by cells, tissues and organs, or are attached to native substances that subsequently migrate to an inflammatory focus. Because they provide different types of information, anatomical and molecular imaging studies are complementary to each another. There are certain situations, however, in which molecular imaging tests are especially valuable: postoperative infections and infections associated with orthopedic hardware, notably prosthetic joint infection. Postoperative infections are a significant cause of morbidity and mortality. Ultrasound, CT and magnetic resonance imaging (MRI) cannot consistently separate abscesses from other fluid collections and, on occasion, even from normal postoperative changes. The distorted anatomy, metallic sutures and the surgical incision itself further complicate study interpretation. Molecular imaging studies, however, demonstrate physiological processes, which often precede anatomical changes, and can help distinguish normal postoperative inflammation from infection. In suspected orthopedic hardware infection, plain radiographs are neither sensitive nor specific and cross-sectional imaging modalities, such as CT and MRI, are limited by hardwareinduced artifacts. Radionuclide imaging is not affected by metallic hardware and is the current imaging modality of choice for diagnosing orthopedic hardware infection.

This article reviews the various radiolabeled molecular imaging agents used for detecting and localizing inflammation and infection as well as the potential role of these agents in guiding selection of therapeutic agents and monitoring treatment response.

\section{Single photon-emitting (SPECT) tracers}

\section{Non-specific agents}

\section{Gallium-67 citrate}

Several factors contribute to gallium-67 citrate $\left({ }^{67} \mathrm{Ga}\right.$ citrate) uptake in inflammation and infection. About $90 \%$ of circulating $\mathrm{Ga}$ ions are bound to transferrin in the plasma. Increased blood flow and vascular membrane permeability result in increased ${ }^{67} \mathrm{Ga}$ delivery and accumulation at the inflammatory foci. ${ }^{67} \mathrm{Ga}$ also binds to lactoferrin, which is present in high concentrations in inflammatory foci. Direct bacterial uptake, complexing with siderophores and leukocyte transport also contribute to ${ }^{67} \mathrm{Ga}$ uptake in inflammation and infection. Imaging usually is performed $18-72 \mathrm{~h}$ after injection. The normal distribution of ${ }^{67} \mathrm{Ga}$, which is variable, includes bone, marrow, liver, gastrointestinal and urinary tracts, and soft tissues [1].

Replaced by labeled leukocyte imaging for most indications, ${ }^{67} \mathrm{Ga}$ remains useful in select circumstances. Opportunistic infections affect the lungs, and a normal scan of the chest excludes infection with a high degree of certainty. In HIV-positive patients, lymph node uptake is associated with mycobacterial infection and lymphoma. Focal, or localized, pulmonary parenchymal uptake usually is associated with bacterial pneumonia. Diffuse pulmonary uptake, especially when intense, suggests Pneumocystis jirovecii pneumonia [1].

${ }^{67} \mathrm{Ga}$ is a sensitive indicator of pulmonary inflammation and accumulates in interstitial pneumonitis, drug reactions, collagen vascular disease, pneumoconioses and sarcoidosis. In patients with sarcoidosis, uptake correlates with disease activity and response to therapy [1].

${ }^{67} \mathrm{Ga}$ can help differentiate interstitial nephritis from acute tubular necrosis in patients with acute renal failure. Interstitial nephritis is characterized by renal uptake that is more intense than lumbar spine uptake. Acute tubular necrosis is characterized by little or no renal uptake [1] (Fig. 1).

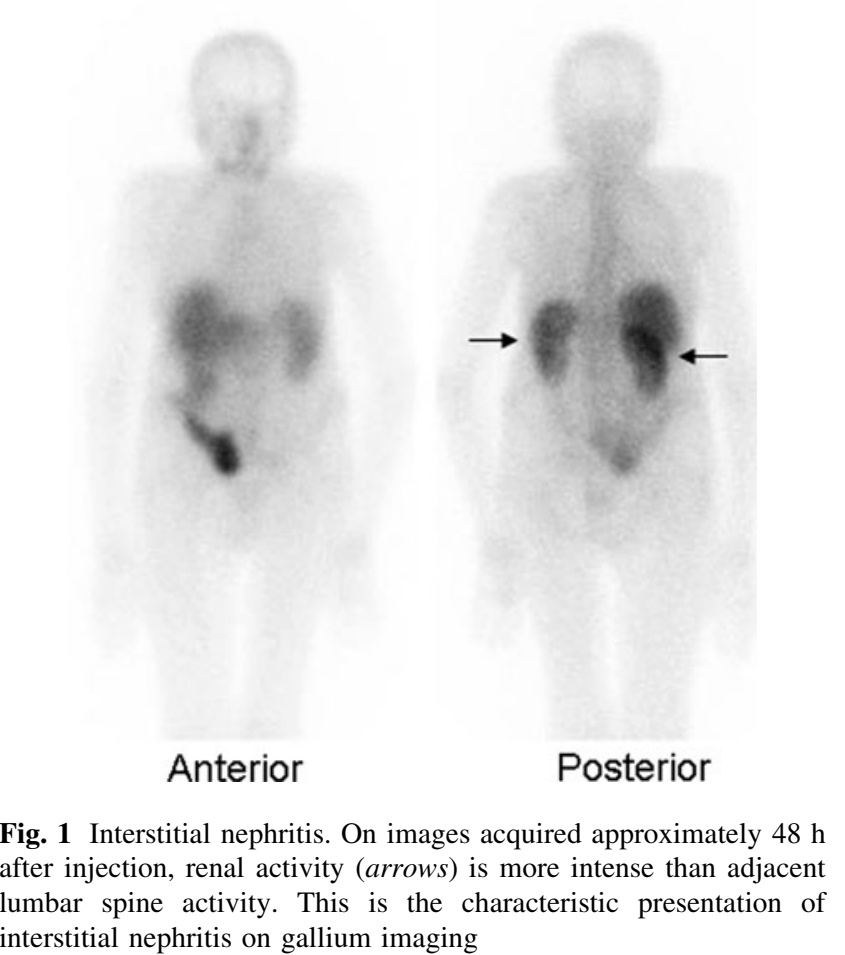


Although $\left[{ }^{18} \mathrm{~F}\right]$ fluorodeoxyglucose $\left(\left[{ }^{18} \mathrm{~F}\right] \mathrm{FDG}\right)$ PET is the radionuclide test of choice for fever of unknown origin and spinal osteomyelitis, ${ }^{67} \mathrm{Ga}$ is an acceptable alternative when this agent is not available [1].

\section{Labeled leukocytes}

In vitro labeled leukocytes In vitro leukocyte (WBC) labeling usually is performed with ${ }^{111}$ In-oxyquinolone $\left({ }^{111} \mathrm{In}\right)$ or ${ }^{99 \mathrm{~m}} \mathrm{Tc}$-exametazime $\left({ }^{99 \mathrm{~m}} \mathrm{Tc}-\mathrm{HMPAO}\right)$. Uptake depends on intact chemotaxis, number and types of cells labeled and cellular response in a particular condition. A circulating WBC count of at least $2,000 / \mu \mathrm{L}$ is needed for satisfactory images. Although a mixed population of WBCs is labeled, the majority of WBCs labeled are usually neutrophils and the procedure is most sensitive for identifying neutrophil-mediated infectious processes [2]. It is possible to selectively label granulocytes. To do so, however, requires the use of a gradient separation process, further lengthening an already labor-intensive process. Published results, in general, have shown no real advantage of radiolabeled granulocytes over radiolabeled leukocytes for routine clinical use [3].

Images obtained shortly after injection of labeled WBCs are characterized by intense pulmonary activity, which clears rapidly. This phenomenon probably results from WBC activation during labeling, which impedes cell movement through the pulmonary vascular bed and prolongs transit through the lungs [2].

The advantages of In-WBCs include label stability, a normal distribution limited to liver, spleen and bone marrow and the possibility of performing delayed imaging. Complementary bone marrow imaging can be performed during cell labeling, as a simultaneous dual isotope acquisition, or after ${ }^{111}$ In-WBC imaging. Disadvantages include low counts, low-resolution images and the 16-30 h interval between injection and imaging [2].

The normal distribution of ${ }^{99 \mathrm{~m}} \mathrm{Tc}-\mathrm{HMPAO}-\mathrm{WBC}$ is more variable than that of ${ }^{111} \mathrm{In}-\mathrm{WBC}$. In addition to the reticuloendothelial system, activity is normally present in the urinary tract, large bowel (within $4 \mathrm{~h}$ of injection) and occasionally gallbladder. The advantages of ${ }^{99 \mathrm{~m}} \mathrm{Tc}$ HMPAO-WBCs include high-resolution images and the capacity of the technique to detect abnormalities within a few hours of injection. Disadvantages include label instability and the short half-life of ${ }^{99 \mathrm{~m}} \mathrm{Tc}$, which limits the possibility of performing delayed imaging. When performing bone marrow imaging, an interval of $48-72 \mathrm{~h}$ is required between the two imaging procedures [2].

In the brain, MRI can, in most cases, differentiate tumors from abscesses. When MRI cannot be performed or is not diagnostic, WBC imaging is a useful alternative, being both sensitive and specific. WBC uptake has been observed in some tumors, but usually is less intense than that observed in abscesses. High- or medium-dose steroid treatment may decrease sensitivity [4-6].

Pneumonia is easily and accurately diagnosed with morphological imaging tests and consequently molecular imaging rarely is needed to diagnose pulmonary infection. Focal pulmonary activity on WBC images that is segmental or lobar in appearance indicates a high likelihood of pyogenic infection. Diffuse, bilateral pulmonary uptake is associated with numerous conditions including opportunistic infection, pulmonary drug toxicity and acute respiratory distress syndrome (ARDS), but almost never with bacterial pneumonia [7].

Radionuclide imaging, traditionally, has played a limited role in diagnosing bacterial endocarditis; recent data suggest, however, that ${ }^{99 \mathrm{~m}} \mathrm{Tc}-\mathrm{HMPAO}-\mathrm{WBC}$ SPECT/CT contributes useful information in patients suspected of having this condition [8]. The value of WBC imaging for diagnosing complications of bacterial endocarditis, such as myocardial abscesses and mycotic aneurysms, is already well established [2, 9]. WBC imaging is also useful for diagnosing prosthetic vascular graft infection. The reported sensitivity, which in most series exceeds $90 \%$, is not affected by antibiotic therapy or duration of symptoms. Specificity ranges from 50 to $100 \%$. False-positive results are associated with lymphoceles, perigraft hematomas, thrombosed grafts, bleeding, pseudoaneurysms and uninfected grafts $<1$-month-old [2].

In the postoperative patient, morphological imaging techniques cannot consistently separate abscesses from other fluid collections, or even from normal postoperative changes. WBC imaging provides physiological information and is complementary to these techniques [10].

${ }^{99 \mathrm{~m}}$ Tc-HMPAO-WBC imaging, the radionuclide study of choice for inflammatory bowel disease (IBD), is very sensitive and can be used as a screening test. In patients thought to have ulcerative, or indeterminate, colitis, skip areas of activity in the colon, or the presence of small bowel activity, support the diagnosis of Crohn's disease. The test is useful in patients who cannot or will not undergo endoscopy or contrast radiography can be used to monitor response to therapy and can impact on patient management by differentiating active inflammation from scarring. Imaging at multiple time points and SPECT both increase sensitivity. ${ }^{99 \mathrm{~m}} \mathrm{Tc}-\mathrm{HMPAO}-\mathrm{WBC}$ is more sensitive for lower than for upper gastrointestinal tract disease. Its sensitivity may be affected adversely by concomitant corticosteroid administration [11].

WBC imaging of diabetic pedal osteomyelitis has been extensively investigated. The sensitivity of ${ }^{111} \mathrm{In}-\mathrm{WBC}$ in diabetic foot infections ranges from 72 to $100 \%$ and the specificity from 67 to $100 \%$. The sensitivity and specificity of ${ }^{99 \mathrm{~m}}$ Tc-HMPAO-WBC range from 86 to $93 \%$ and from 80 
Fig. 2 Soft tissue infection, right great toe. There is focally increased activity (arrows) in the right great toe on the dorsal and plantar images (a) obtained approximately $6 \mathrm{~h}$ after injection of ${ }^{99 \mathrm{~m}} \mathrm{Tc}$ exametazime-labeled autologous leukocytes. It is not possible to determine whether the infection involves bone. The SPECT/CT (b) confirms that the infection (arrows) is confined to the soft tissues
A

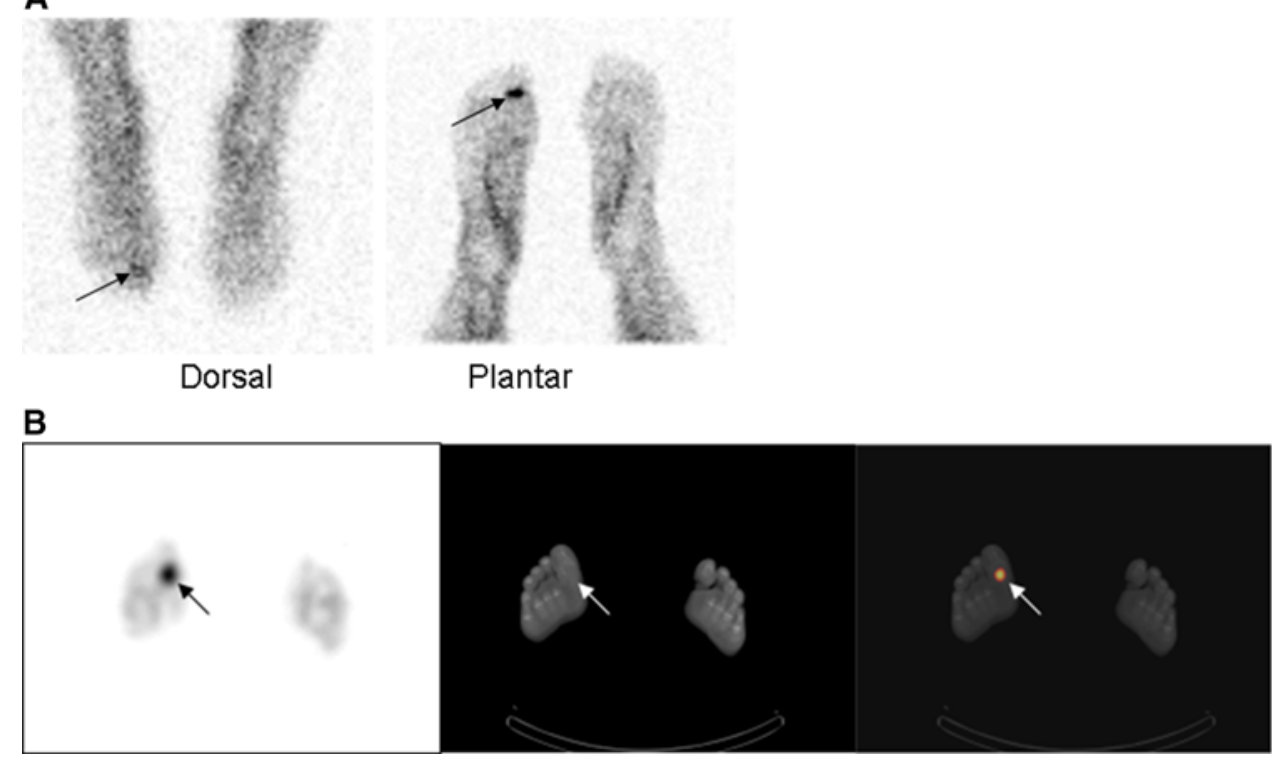

to $98 \%$, respectively. SPECT/CT improves test accuracy [12-15] (Fig. 2). In a recent investigation, ${ }^{99 \mathrm{~m}} \mathrm{Tc}-\mathrm{HMPAO}-$ WBC imaging was found to be more accurate than $\left[{ }^{18} \mathrm{~F}\right] \mathrm{FDG}$ PET/CT for diagnosing pedal osteomyelitis in diabetics [16].

WBC imaging is not useful for diagnosing spinal osteomyelitis; $50 \%$ or more of these cases present as nonspecific areas of decreased or absent activity. $\left[{ }^{18} \mathrm{~F}\right] \mathrm{FDG}$ PET, or alternatively ${ }^{67} \mathrm{Ga}$-citrate scintigraphy, is the preferred nuclear medicine test for this indication [17].

WBC imaging, the procedure of choice for diagnosing complicating osteomyelitis, is frequently performed together with colloid bone marrow imaging. The reason for this is that WBCs accumulate not only in sites of infection, but also in the bone marrow. The normal distribution of hematopoietically active bone marrow in adults is variable. Systemic diseases such as sickle cell and Gaucher disease produce generalized alterations in marrow distribution; fractures, orthopedic hardware and neuropathic joints cause localized alterations. The normal distribution of hematopoietically active marrow in children varies with age. Consequently, it may not be possible to determine whether an area of activity on a WBC image represents infection or marrow. Performing ${ }^{99 \mathrm{~m}}$ Tc-colloid bone marrow imaging overcomes this problem. Both WBCs and colloid accumulate in marrow; WBCs also accumulate in infection, but colloid does not. The combined study is positive for infection when activity is present on the WBC image without corresponding activity on the marrow image. Any other pattern is negative for infection. The combined study has been most extensively investigated in prosthetic joint infections, but is valuable in any condition that affects marrow distribution, showing an overall accuracy of approximately $90 \%$ [18] (Fig. 3).
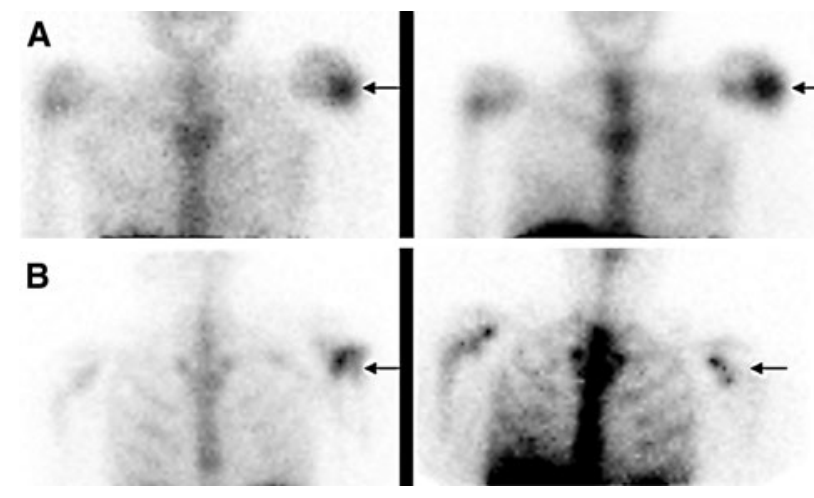

Fig. 3 a Hypercellular bone marrow. On the ${ }^{111}$ In-labeled leukocyte image (left), acquired $24 \mathrm{~h}$ after injection of autologous labeled leukocytes, there is focally increased activity in the left shoulder of a patient with sickle cell disease, who presented with fever and left shoulder pain. The distribution of activity is virtually identical on the bone marrow image (right), which was performed immediately after the labeled leukocyte imaging, and $1 \mathrm{~h}$ after injection of ${ }^{99 \mathrm{~m}} \mathrm{Tc}$-sulfur colloid and hence the test is negative for osteomyelitis. The increased activity in the left shoulder is the result of localized marrow hyperplasia. b Osteomyelitis, left shoulder. On the ${ }^{99 \mathrm{~m}} \mathrm{Tc}$-exametazime image (left), acquired approximately $16 \mathrm{~h}$ after injection of labeled autologous leukocytes, there is focally increased activity in the left shoulder (arrow) of a patient who presented with shoulder pain, fever and positive blood cultures. On the bone marrow image (right), which was performed $1 \mathrm{~h}$ after injection of ${ }^{99 \mathrm{~m}} \mathrm{Tc}$-sulfur colloid and 2 days after the labeled leukocyte study, the left shoulder is photopenic (arrow) and the test is positive for osteomyelitis

As an alternative to marrow imaging, dual time point imaging (delayed images obtained 3-4 h after reinjection and late images 20-24 h after reinjection), with acquisition times corrected for ${ }^{99 \mathrm{~m}} \mathrm{Tc}$ decay, has been suggested. Decay-corrected images avoid operator bias and the fact of using the same count scale in all images facilitates 
image interpretation. Increasing uptake, either in size or over time, is considered positive for infection; lack of uptake or decreasing uptake over time is classified as negative for infection. Dual time point imaging with decay-corrected acquisition times may decrease the need for complementary bone marrow imaging, thereby reducing costs as well as radiation exposure to both patients and personnel [19].

In vivo labeled leukocytes Besilesomab (Scintimun ${ }^{\circledR}$ ), a $150 \mathrm{kDa}$ murine monoclonal antibody of the $\mathrm{IgG}_{1}$ kappa isotype, binds to non-specific cross-reacting antigen-95 (NCA-95), an epitope expressed on cell membranes of granulocytes and granulocyte precursors. About $10 \%$ of injected activity is neutrophil bound by $45 \mathrm{~min}$, while $20 \%$ circulates freely and presumably localizes in inflammatory foci through non-specific mechanisms. Studies usually become positive within $6 \mathrm{~h}$ of injection; next-day imaging increases the sensitivity of the test [20].

In one investigation, ${ }^{99 \mathrm{~m}} \mathrm{Tc}$-besilesomab was more sensitive (75 vs $59 \%$ ), but less specific (72 vs $80 \%$ ) than ${ }^{99 \mathrm{~m}}$ Tc-HMPAO-WBC for diagnosing appendicular osteomyelitis [21]. ${ }^{99 \mathrm{~m}} \mathrm{Tc}$-besilesomab has a level of accuracy similar to that of in vitro labeled WBC imaging for diagnosing diabetic pedal osteomyelitis. Results in suspected prosthetic joint infection have been variable. Combining the test with bone scintigraphy, performing semiquantitative analysis and incorporating SPECT/CT into the imaging protocol may improve the accuracy [2, 22, 23].

${ }^{99 \mathrm{~m}}$ Tc-besilesomab accurately diagnoses appendicitis, contributes useful information in patients with pyrexia of unknown origin and may be a useful screening test for acute myocarditis. It is less accurate than ${ }^{99 \mathrm{~m}} \mathrm{Tc}-\mathrm{WBC}$ in inflammatory bowel disease [24-26].

A significant disadvantage of ${ }^{99 \mathrm{~m}} \mathrm{Tc}$-besilesomab is the incidence of human antimurine antibody (HAMA) response, which ranges from $<5 \%$ in patients receiving a single dose of $125 \mu \mathrm{g}$ of antibody to more than $30 \%$ in patients receiving repeated injections [20]. To minimize potential problems, patients should be prescreened for HAMA, a maximum of $250 \mu \mathrm{g}$ antibody should be injected and repeated administrations should be avoided.

Fanolesomab $\left(\right.$ LeuTech $^{\circledR}, \quad$ NeutroSpec $^{\circledR}$ ) is a $900 \mathrm{kDa}$ M class immunoglobulin that exhibits a high affinity for 3-fucosyl- $N$-acetyl lactosamine contained in the CD15 antigen expressed on human leukocytes. Accumulation in infection is via binding to circulating neutrophils that subsequently migrate to infection and bind to neutrophils and neutrophil debris already sequestered in an infection. ${ }^{99 \mathrm{~m}} \mathrm{Tc}$-fanolesomab accurately diagnoses atypical appendicitis as well as musculoskeletal and prosthetic vascular graft infections. Following reports of serious and life-threatening cardiopulmonary events, including two fatalities shortly after administration, ${ }^{99 \mathrm{~m}} \mathrm{Tc}$-fanolesomab was withdrawn from the market [2].

Sulesomab (Leukoscan ${ }^{\circledR}$ ) is a $50 \mathrm{kDa}$ fragment antigen binding $\left(\mathrm{Fab}^{\prime}\right)$ portion of an $\mathrm{IgG}_{1}$ class murine monoclonal antibody that binds to normal cross-reactive antigen-90 (NCA-90) present on leukocytes. Approximately, 3-6\% of the injected activity is associated with circulating neutrophils; at $24 \mathrm{~h}$ after injection, about $35 \%$ of the remaining activity is in the bone marrow. Initial investigations suggested that sulesomab binds to circulating neutrophils that migrate to foci of infection and to leukocytes already present at the site of infection. Recent data, however, suggest that the accumulation in infection is non-specific [2].

Most investigations have found that ${ }^{99 \mathrm{~m}} \mathrm{Tc}$-sulesomab is sensitive for diagnosing musculoskeletal infection. Specificity is variable, especially in suspected prosthetic joint infection. ${ }^{99 \mathrm{~m}} \mathrm{Tc}$-sulesomab is comparable to in vitro labeled WBC imaging for diagnosing pedal osteomyelitis in diabetics (Fig. 4). The test is reasonably accurate for diagnosing soft tissue infections and pyrexia of unknown origin, but is less useful for inflammatory bowel disease [2]. ${ }^{99 \mathrm{~m}} \mathrm{Tc}$-sulesomab may have a role in implanted deep brain stimulation device infections. Imaging results correlate well with the presence and extent of infection, thereby facilitating patient management [27].

Most techniques for labeling leukocytes in vivo use antigranulocyte antibodies or antibody fragments. Cytokines, low molecular weight proteins that interact with specific cell-surface receptors on specific cell populations, also have been investigated.

Interleukin 8 (IL-8) is a member of the CXC subfamily of chemotactic cytokines that binds with high affinity to the CXC type I (IL-8 type A) and CXC type II (IL-8 type B) receptors expressed on neutrophils and monocytes. The agent is well tolerated, rapidly accumulates at sites of infection and clears rapidly from the blood pool and nontarget tissues. In a rabbit model of acute osteomyelitis, ${ }^{99 \mathrm{~m}}$ Tc-IL-8 clearly showed the area of osteomyelitis [2830].

Although the majority of investigations have focused on labeling granulocytes for infection localization, some investigators have used labeled lymphocytes to study inflammatory conditions. Interleukin 2 (IL-2) is synthesized and secreted by $\mathrm{T}$ lymphocytes and binds with high affinity to IL-2 receptors expressed by activated lymphocytes during inflammation. Radioabeled IL-2 allows visualization of both lymphocytic infiltration and $\mathrm{T}$ cell lymphocyte activation and has been used in several inflammatory diseases characterized by chronic lymphocytic infiltration, such as Takayasu's arteritis, diabetes mellitus, celiac disease, Crohn's disease, autoimmune thyroid diseases and atherosclerosis [31]. 


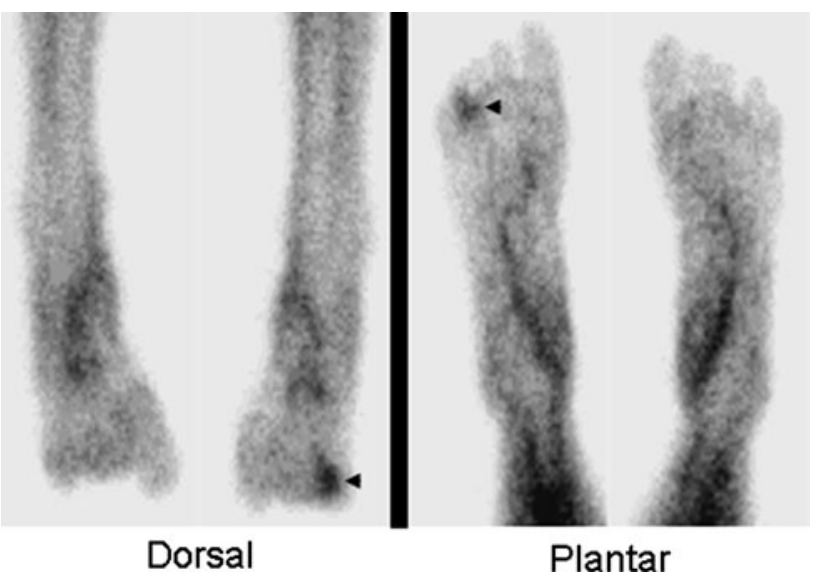

Fig. 4 Diabetic pedal osteomyelitis. There is focally increased radionuclide uptake in the right fourth toe (arrowheads) on images acquired approximately $1 \mathrm{~h}$ after injection of ${ }^{99 \mathrm{~m}} \mathrm{Tc}$-sulesomab. Published data suggest that the accuracy of ${ }^{99 \mathrm{~m}} \mathrm{Tc}$-sulesomab for diagnosing pedal osteomyelitis in diabetics is similar to that of in vitro labeled leukocytes

Infection-specific agents

\section{Radiolabeled antibiotics}

None of the clinically available agents is truly specific for infection, and the search continues for such an agent. Radiolabeled antibiotics have been investigated as "infection-specific" tracers. Presumably, the labeled antibiotic is incorporated into, and metabolized by, bacteria and assuming that uptake is proportional to the number of microorganisms present, the measured radioactivity would accurately and specifically localize infection. The most extensively investigated radiolabeled antibiotic, ${ }^{99 \mathrm{~m}} \mathrm{Tc}-$ ciprofloxacin, was initially reported to be both sensitive and specific for infection [32, 33]. Subsequent investigations, however, raised serious doubts about this agent as an infection-specific tracer and much of the original enthusiasm for radiolabeled antibiotics as diagnostic tools has waned [34-36].

\section{${ }^{111}$ In-Biotin}

Biotin is necessary for cell growth, fatty acid production and metabolism of fats and amino acids, and it serves as a growth factor for certain bacteria. ${ }^{111}$ In-Biotin, alone or in combination with streptavidin, accurately diagnoses spinal infections and may be a useful alternative to $\left[{ }^{18} \mathrm{~F}\right] \mathrm{FDG}$ PET and ${ }^{67} \mathrm{Ga}$-citrate imaging. ${ }^{111} \mathrm{In}$-Biotin does not accumulate in normal bone or marrow, so there are no anatomical landmarks, and SPECT/CT is especially helpful for correctly localizing foci of ${ }^{111}$ In-Biotin accumulation and guiding the selection of therapy $[37,38]$.

\section{Radiolabeled antimicrobial peptides}

Antimicrobial peptides are critical to the biological defenses of multicellular organisms. They are produced by various cells, including phagocytes, and endothelial and epithelial cells, and bind to the bacterial cell membrane. Their expression may be constant or induced on contact with microbes; they may also be transported to sites of infection by leukocytes [39].

Radiolabeled synthetic fragments of ubiquicidin (UBI), a naturally occurring human antimicrobial peptide that targets bacteria, possess the ability to differentiate infection from sterile inflammation [40]. ${ }^{99 \mathrm{~m}}$ Tc-UBI $29-41$ may be useful for monitoring the efficacy of antibacterial agents in infections caused by Staphylococcus aureus [41, 42]. In an animal model of prosthetic joint infection, all six infected devices were positive on day 9 , but only four of the six were positive on day 20 . The decreased sensitivity over time may have been related to effects of the protective glycocalyx secreted by the bacteria [43].

Available human data are encouraging. In six children with suspected osteomyelitis, tracer cleared rapidly from the circulation with a mean residence time of about $30 \mathrm{~min}$. Approximately, $85 \%$ of the injected activity was eliminated by renal clearance within $24 \mathrm{~h}$. There was minimal accumulation in non-target tissues with an average target/ non-target ratio of $2.18 \pm 0.74$ in positive lesions at $2 \mathrm{~h}$ [39]. The sensitivity, specificity and accuracy of ${ }^{99 m} \mathrm{Tc}-$ UBI 29-41 in 18 patients suspected of having various infections were 100, 80 and $94.4 \%$, respectively. Optimal visualization of abnormalities occurred about $30 \mathrm{~min}$ after injection [44]. ${ }^{99 \mathrm{~m}} \mathrm{Tc}-\mathrm{UBI} 29-41$ detected five out of six cases of mediastinitis among 13 patients who had recently undergone cardiac surgery [45]. A recent meta-analysis reported that the pooled sensitivity, specificity and accuracy of ${ }^{99 \mathrm{~m}}$ Tc-ubiqicidin were $94.5,92.7$ and $93.7 \%$ [46].

${ }^{99 \mathrm{~m}}$ Tc-labeled recombinant human beta-defensin-3 (HBD-3) that exerts bactericidal effects on Gram-positive and Gram-negative bacteria has also been investigated. By $3 \mathrm{~h}$ after injection, tracer uptake in a Staphylococcus aureus infection model was significantly higher than that in sterile inflammation [47].

\section{Positron-emitting (PET) tracers}

In general, positron emission tomography (PET) offers several advantages over SPECT imaging. PET provides three-dimensional images of the whole body with superior resolution and facilitates [especially, when combined with CT (PET/CT)] precise localization of abnormal uptake. Furthermore, semiquantitative analysis is more readily available and could be helpful for differentiating between 


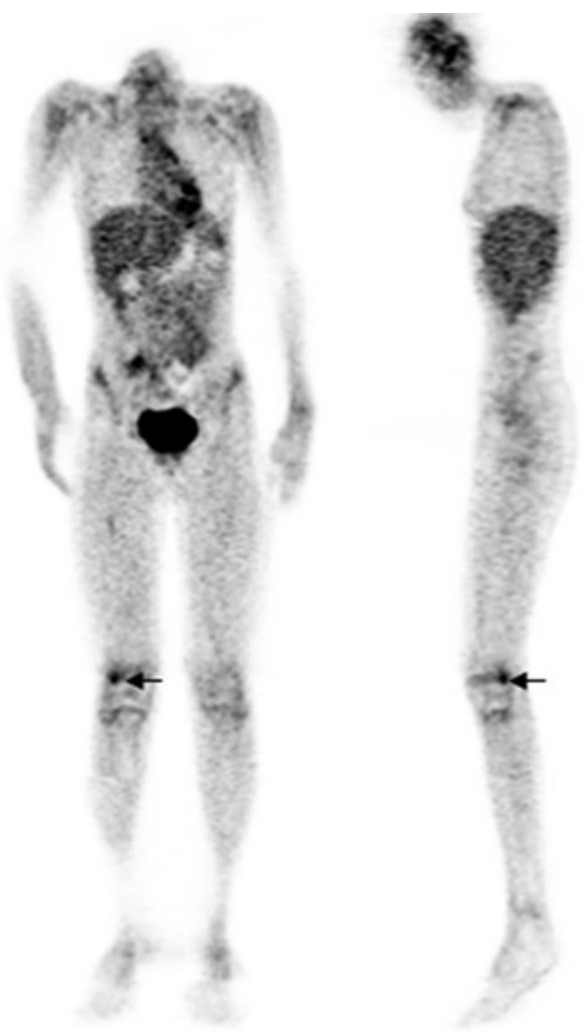

Fig. 5 Right femur osteomyelitis. There is focal hypermetabolism (arrows) in the lateral condyle of the distal right femur on the coronal and sagittal $\left[{ }^{18}\right.$ F]FDG PET images of a 12-year-old leukopenic patient with Staphylococcus aureus bacteremia and right knee pain. Imaging was performed approximately $1 \mathrm{~h}$ after $\left[{ }^{18} \mathrm{~F}\right] \mathrm{FDG}$ injection

infections and other causes of uptake, as well for monitoring response to therapy.

Non-specific agents

\section{$\left[{ }^{18}\right.$ F]Fluorodeoxyglucose}

$\left[{ }^{18} \mathrm{~F}\right] \mathrm{FDG}$, a well-established tool in oncology, has been an increasing focus of attention in the field of infection and inflammation imaging over the past decade, since $\left[{ }^{18} \mathrm{~F}\right] \mathrm{FDG}$ also accumulates in activated leukocytes, which use glucose as an energy source only after activation during their metabolic burst [31]. Transport of $\left[{ }^{18} \mathrm{~F}\right] \mathrm{FDG}$ across the cell membrane is mediated by glucose transporter proteins (GLUT). Intracellular $\left[{ }^{18} \mathrm{~F}\right] \mathrm{FDG}$ is phosphorylated by the enzyme hexokinase and trapped in the cell. With the exception of a few organs, physiological uptake of $\left[{ }^{18} \mathrm{~F}\right] \mathrm{FDG}$ is low and clearance from non-target tissue is rapid, resulting in relatively high target-to-background ratios. With the new hybrid PET/CT systems, diagnostic evaluation can be completed in a single visit in just $1-2 \mathrm{~h}$ (including the waiting time, after injection, necessary for sufficient tracer uptake). Compared with many other

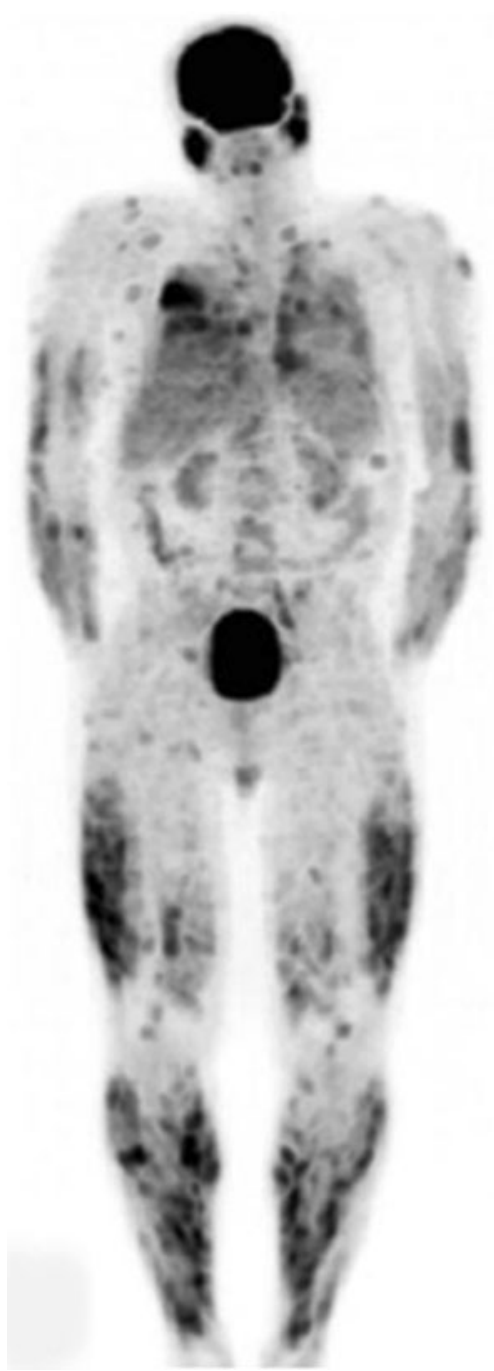

Fig. 6 Sarcoidosis. Anterior maximum intensity projection image (MIP) acquired approximately $1 \mathrm{~h}$ after $\left[{ }^{18} \mathrm{~F}\right] \mathrm{FDG}$ injection demonstrates innumerable pulmonary and cutaneous foci of hypermetabolism in a patient with disseminated active sarcoidosis

radiopharmaceuticals, $\left[{ }^{18} \mathrm{~F}\right] \mathrm{FDG}$ has a very favorable dosimetry. It is very sensitive and in most situations has a high negative predictive value. There are, however, limitations to this agent, notably its specificity. $\left[{ }^{18} \mathrm{~F}\right] \mathrm{FDG}$ PET merely detects enhanced glucose metabolism and is therefore unable to discriminate reliably between infection/ inflammation, malignancy and any other hypermetabolic state. $\left[{ }^{18} \mathrm{~F}\right] \mathrm{FDG}$ also cannot distinguish between different inflammatory pathways, which can be relevant in some clinical situations [31].

Combined EANM/SNMMI guidelines for the use of $\left[{ }^{18} \mathrm{~F}\right] \mathrm{FDG}$ in infection and inflammation have been published. Major indications are peripheral bone osteomyelitis (non-postoperative, non-diabetic foot) (Fig. 5), sarcoidosis (Fig. 6), suspected spinal infection (Fig. 7), evaluation of fever of unknown origin (FUO), evaluation of metastatic 
Fig. 7 Spinal osteomyelitis/ infected spinal hardware. On the sagittal images from the PET/ CT scan, performed approximately $1 \mathrm{~h}$ after $\left[{ }^{18} \mathrm{~F}\right] \mathrm{FDG}$ injection, there is spinal hypermetabolism extending from approximately T11 to L3 (arrows), with a maximum SUV of 9.3 (color figure online)
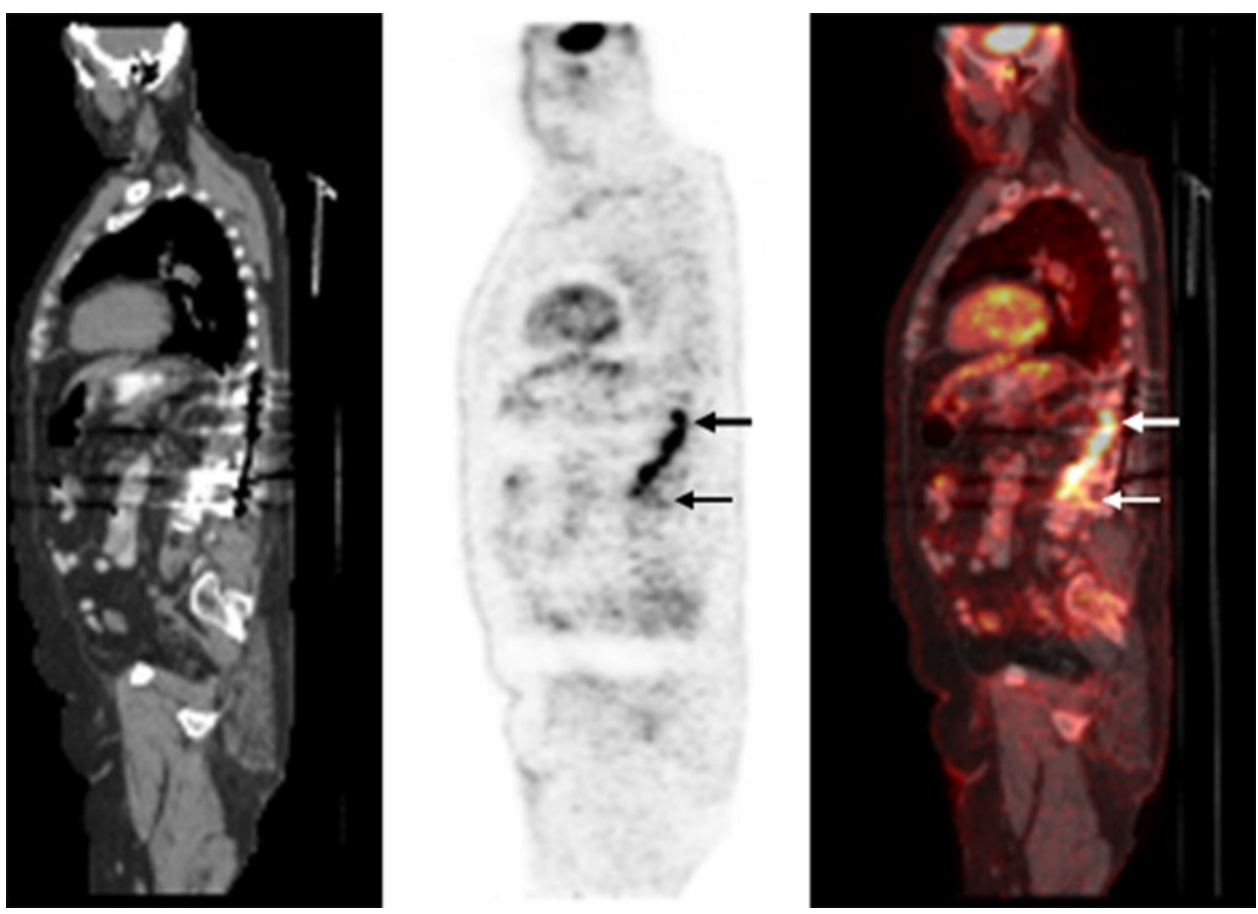

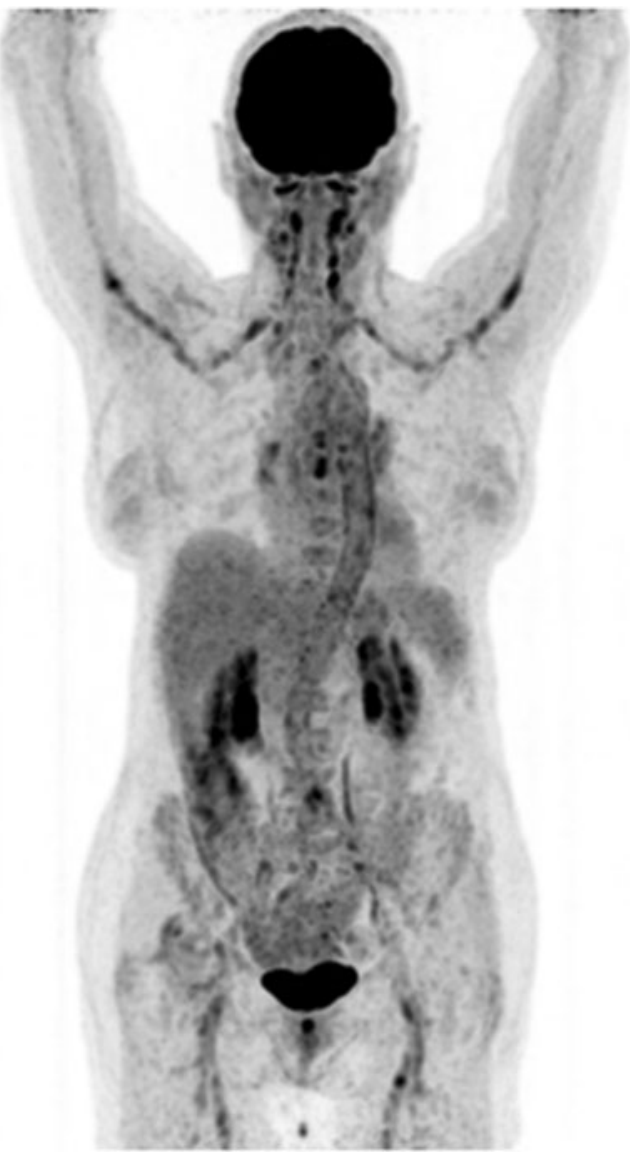

Fig. 8 Giant cell arteritis. Note the intense, relatively homogeneous $\left[{ }^{18} \mathrm{~F}\right] \mathrm{FDG}$ accumulation in the carotid and subclavian arteries, as well as in the aortic arch, thoracic and abdominal aorta, and the iliac and femoral arteries. Imaging was performed about $1 \mathrm{~h}$ after injection of tracer infection and high-risk patients with bacteremia, and primary evaluation of suspected vasculitis (Fig. 8) [48].

$\left[{ }^{18} \mathrm{~F}\right] \mathrm{FDG}$ may be useful for diagnosing infected hepatic and renal cysts, infected intravascular devices and AIDSassociated opportunistic infections and for assessing tuberculous lesions. Sufficient evidence-based data for these indications, however, are currently lacking [48].

While specificity is usually the limiting factor in $\left[{ }^{18}\right.$ F]FDG imaging, there are some situations in which the limitation is low sensitivity, e.g., in prosthetic joint infections, diabetic foot infections and in the evaluation of medium- and small-vessel vasculitis [49].

\section{$\left[{ }^{18} \mathrm{~F}\right] F D G$-labeled leukocytes}

Leukocytes have been labeled in vitro with $\left[{ }^{18} \mathrm{~F}\right] \mathrm{FDG}$ in an attempt to develop a more specific PET tracer. Whole-body and organ dosimetry are comparable to those of conventional doses of ${ }^{111}$ In-WBCs [50]. Initial results were encouraging [51, 52]. However, the labeling efficiency is low and may be affected by blood glucose levels [53]. In some indolent infections, labeled leukocyte accumulation is slow and imaging at later time points (e.g., $24 \mathrm{~h}$ ) may be necessary to detect the abnormality. Given the short halflife of ${ }^{18} \mathrm{~F}(110 \mathrm{~min})$, it is technically not feasible to perform imaging much later than $4-5 \mathrm{~h}$ after injection. Although there are some data indicating different distribution patterns between $\left[{ }^{18} \mathrm{~F}\right] \mathrm{FDG}$ and $\left[{ }^{18} \mathrm{~F}\right] \mathrm{FDG}$-labeled leukocytes (suggesting improved specificity of the coupled tracer), well-designed clinical trials demonstrating an 
added value of $\left[{ }^{18} \mathrm{~F}\right] \mathrm{FDG}$-labeled leukocytes versus $\left[{ }^{18}\right.$ F]FDG are lacking $[54,55]$.

\section{Copper-64-labeled agents}

Copper-64 $\left({ }^{64} \mathrm{Cu}\right)$, theoretically, is one of the more suitable PET isotopes for imaging purposes. Its physical half-life of $12.7 \mathrm{~h}$ makes it a suitable tracer for imaging infectious and inflammatory diseases. In ten volunteers, leukocytes were labeled in vitro with ${ }^{64} \mathrm{Cu}$, In and $\left[{ }^{18} \mathrm{~F}\right] \mathrm{FDG} .{ }^{64} \mathrm{Cu}-\mathrm{WBC}$ labeling efficiency and viability were comparable or superior to those of ${ }^{111} \mathrm{In}-\mathrm{WBC}$ and significantly higher than those of $\left[{ }^{18} \mathrm{~F}\right]$ FDG-WBC. ${ }^{64} \mathrm{Cu}$ was retained inside the cells without evident toxicity. These data suggest that ${ }^{64} \mathrm{Cu}$-labeled leukocytes may potentially be useful for imaging inflammation and infection and further investigation is warranted [56].

However, the shortage of appropriate chelating agents has, to date, limited the wider application of ${ }^{64} \mathrm{Cu}$ [57]. New developments in ${ }^{64} \mathrm{Cu}$ imaging focus primarily on cancer research. ${ }^{64} \mathrm{Cu}$-labeled natriuretic peptide is a potential tracer for the in vivo imaging of atherosclerotic plaques [58]. Mice with induced colitis, compared with control groups, were found to show higher uptake of a ${ }^{64} \mathrm{Cu}$-labeled anti- $\beta 7$ integrin antibody [59]. Recently, in an in vitro investigation, chitosan-coated magnetic ${ }^{64} \mathrm{Cu}$ nanoparticles were found to be taken up by granuloctyes through phagocytosis, and showed a high stability (of up to $80 \%$ ) of retained activity after $24 \mathrm{~h}$ of incubation [60].

\section{Gallium-68 citrate}

The imaging characteristics of the positron emitter gallium$68\left({ }^{68} \mathrm{Ga}\right)$ are superior to those of ${ }^{67} \mathrm{Ga}$ by virtue of the higher spatial resolution and quantitative features of PET in comparison with single-photon imaging. ${ }^{68} \mathrm{Ga}$-citrate has suitable radiophysical and radiopharmaceutical properties: high positron yield and a half-life of $68 \mathrm{~min}$, and thus, showing rapid blood clearance, quick diffusion and target localization, is able to match the pharmacokinetics of many peptides and other small molecules [61]. In addition, this agent can be generator produced, and several generators are commercially available.

${ }^{68} \mathrm{Ga}$-citrate is produced with high radiochemical yield and purity and can be used in the detection of inflammatory and infectious diseases [62]. However, large clinical trials are still lacking. The largest series to date consisted of 31 patients with suspected osteomyelitis or discitis who underwent a total of $40{ }^{68} \mathrm{Ga}$-citrate PET/CT scans. An overall accuracy of $90 \%$ was found, and the authors stated that the possible role of ${ }^{68} \mathrm{Ga}$-citrate in the diagnosis of bone infections was confirmed [63]. While ${ }^{68} \mathrm{Ga}$-citrate may be superior to ${ }^{67} \mathrm{Ga}$-citrate, to adequately assess its value as an inflammation/infection imaging agent it must be compared to $\left[{ }^{18} \mathrm{~F}\right] \mathrm{FDG}$, which, when available, has replaced ${ }^{67} \mathrm{Ga}$.

It is likely that if ${ }^{68} \mathrm{Ga}$-citrate is to be useful in inflammation/infection imaging, it will need to be complexed with other agents. Some molecules have, in fact, been complexed with ${ }^{68} \mathrm{Ga}$ for this purpose. ${ }^{68} \mathrm{Ga}$-apo-transferrin, for example, detected Staphylococcus aureus infection in a rat model within an hour of injection [64]. The specific detection of Aspergillus fumigatus infection in rodent models using ${ }^{68} \mathrm{Ga}$-labeled siderophores has also been described $[65,66]$.

Infection-specific agents

\section{${ }^{124}$ I-FIAU}

The radioiodinated thymidine analog fialuridine (FIAU) is a tracer that has been developed for reporter genes, for cells that were transfected with herpes simplex virus thymidine kinase (HSV-TK). FIAU, because of the homology between viral and bacterial TK, is also a specific substrate of bacterial TK [67]. Localized infections caused by five genera of bacteria have been imaged successfully with ${ }^{125} \mathrm{I}$ FIAU [68]. Data also suggest that this tracer can be used to monitor the efficacy of antimicrobial therapy, because in a preclinical model of lung infection ${ }^{125}$ I-FIAU signal intensity was proportional to the bacterial load. It was suggested that imaging with FIAU could potentially be used to evaluate the efficacy of newly developed antibiotics [69]. The feasibility of using ${ }^{124}$ I-FIAU for diagnosing infection in humans was demonstrated in an investigation of nine subjects, including eight with suspected musculoskeletal infection and one healthy control. All patients with proven musculoskeletal infections demonstrated ${ }^{124}$ I-FIAU accumulation at the site of infection by $2 \mathrm{~h}$ after injection. There was no abnormal tracer uptake in the one control and there were no adverse reactions among any of the subjects [70]. The role of ${ }^{124}$ I-FIAU as a diagnostic imaging agent for diagnosing prosthetic joint infection is under investigation.

\section{Therapy}

As is evident from this review, SPECT and PET tracers play an important role in the diagnosis of inflammation and infection. Though less extensively investigated, molecular imaging also has the potential to guide therapeutic management and to assess response to therapy. Imaging with the radiolabeled anti-tumor necrosis factor alpha (anti$\mathrm{TNF} \alpha$ ) monoclonal antibodies infliximab and adalimumab, for example, has been shown to be of value both for 
identifying patients with Crohn's disease and rheumatoid arthritis who would benefit from anti-TNF $\alpha$ therapy, and for monitoring response to treatment $[71,72]$.

The ability of receptor-based molecular imaging agents to target molecules and cells involved in inflammation and infection has the potential to facilitate the selection of patients for receptor-targeted therapy, and, by monitoring changes in intensity of uptake during and after therapy, to predict response as well as relapse.

Conflict of interest Christopher J. Palestro, M.D. declares that he does not have any conflict of interest, financial or otherwise, with any of the material contained in this manuscript.

Andor W.J.M. Glaudemans, M.D. declares that he does not have any conflict of interest, financial or otherwise, with any of the material contained in this manuscript.

Rudi A.J.O. Dierckx, M.D., Ph.D. declares that he does not have any conflict of interest, financial or otherwise, with any of the material contained in this manuscript.

Human and Animal Studies This article does not contain any studies with human or animal subjects performed by any of the authors.

\section{References}

1. Palestro CJ (2012) Scintigraphic diagnosis of inflammation and infection. In: Brant WE, Helms CA (eds) Fundamentals of diagnostic radiology, 4th edn. Lippincott, Williams \& Wilkins, Philadelphia, pp 1339-1352

2. Palestro CJ, Love C, Bhargava KK (2009) Labeled leukocyte imaging: current status and future directions. Q J Nucl Med Mol Imaging 53:105-123

3. Kumar V (2005) Radiolabeled white blood cells and direct targeting of micro-organisms for infection imaging. Q J Nucl Med Mol Imaging 49:325-338

4. Palestro CJ, Swyer AJ, Kim CK, Muzinic M, Goldsmith SJ (1991) Role of In-111 labeled leukocyte scintigraphy in the diagnosis of intracerebral lesions. Clin Nucl Med 16:305-308

5. Schmidt KG, Rasmussen JW, Frederiksen PB, Kock-Jensen C, Pedersen NT (1990) Indium-111-granulocyte scintigraphy in brain abscess diagnosis: limitations and pitfalls. J Nucl Med 31:1121-1127

6. Kim DG, Lee JL, Lee DS, Lee MC, Choi KS, Han DH (1995) ${ }^{99 m}$ Tc-HMPAO labeled leukocyte SPECT in intracranial lesions. Surg Neurol 44:338-345

7. Love C, Opoku-Agyemang P, Tomas MB, Pugliese PV, Bhargava KK, Palestro CJ (2002) Pulmonary activity on labeled leukocyte images: physiologic, pathologic, and imaging correlations. Radiographics 22:1385-1393

8. Erba PA, Conti U, Lazzeri E, Sollini M, Doria R, De Tommasi SM, Bandera F, Tascini C, Menichetti F, Dierckx RA, Signore A, Mariani G (2012) Added value of ${ }^{99 m}$ Tc-HMPAO-labeled leukocyte SPECT/CT in the characterization and management of patients with infectious endocarditis. J Nucl Med 53:1235-1243

9. Cerqueira MD, Jacobson AF (1989) Indium-111 leukocyte scintigraphic detection of myocardial abscess formation in patients with endocarditis. J Nucl Med 30:703-706

10. Palestro CJ, Love C, Tronco GG, Tomas MB (2000) Role of radionuclide imaging in the diagnosis of postoperative infection. Radiographics 20:1649-1660
11. Palestro CJ (2014) Infection and inflammation. In: Treves ST (ed) Pediatric nuclear medicine and molecular imaging, 4th edn. Springer, New York (in press)

12. Palestro CJ, Love C (2009) Nuclear medicine and diabetic foot infections. Semin Nucl Med 39:52-65

13. Filippi L, Uccioli L, Giurato L, Schillaci O (2009) Diabetic foot infection: usefulness of SPECT/CT for ${ }^{99 \mathrm{~m}} \mathrm{Tc}-\mathrm{HMPAO}-\mathrm{labelled}$ leukocyte imaging. J Nucl Med 50:1042-1046

14. Heiba SI, Kolker D, Mocherla B, Kapoor K, Jiang M, Son H, Rangaswamy B, Kostakoglu L, Savitch I, DaCosta M, Machac J (2010) The optimized evaluation of diabetic foot infection by dual isotope SPECT/CT imaging protocol. J Foot Ankle Surg 49:529-536

15. Erdman WA, Buethe J, Bhore R, Ghayee HK, Thompson C, Maewal P, Anderson J, Klemow S, Oz OK (2012) Indexing severity of diabetic foot infection with ${ }^{99 \mathrm{~m}} \mathrm{Tc}$-WBC SPECT/CT hybrid imaging. Diabetes Care 35:1826-1831

16. Familiari D, Glaudemans AW, Vitale V, Prosperi D, Bagni O, Lenza A, Cavallini M, Scopinaro F, Signore A (2011) Can sequential ${ }^{18} \mathrm{~F}$-FDG PET/CT replace WBC imaging in the diabetic foot? J Nucl Med 52:1012-1019

17. Gemmel F, Dumarey N, Palestro CJ (2006) Radionuclide imaging of spinal infections. Eur $\mathrm{J}$ Nucl Med Mol Imaging 33:1226-1237

18. Palestro CJ, Love C, Tronco GG, Tomas MB, Rini JN (2006) Combined labeled leukocyte and technetium-99m sulfur colloid marrow imaging for diagnosing musculoskeletal infection: principles, technique, interpretation, indications and limitations. Radiographics 26:859-870

19. Glaudemans AW, De Vries EF, Vermeulen LE, Slart RH, Dierckx RA, Signore A (2013) A large retrospective single centre study to define best image acquisition protocols and interpretation criteria for white blood cell scintigraphy with ${ }^{99 \mathrm{~m}} \mathrm{Tc}-\mathrm{HMPAO}$ labelled leukocytes in musculoskeletal infections. Eur J Nucl Med Mol Imaging 40:1760-1769

20. Love C, Palestro CJ (2003) ${ }^{99 \mathrm{~m}}$ Tc-fanolesomab palatin technologies. IDrugs 6:1079-1085

21. Richter WS, Ivancevic V, Meller J, Lang O, Le Guludec D, Szilvazi I, Amthauer H, Chossat F, Dahmane A, Schwenke C, Signore A (2011) ${ }^{99 \mathrm{~m}} \mathrm{Tc}$-besilesomab (Scintimun ${ }^{\circledR}$ ) in peripheral osteomyelitis: comparison with ${ }^{99 \mathrm{~m}} \mathrm{Tc}$-labelled white blood cells. Eur J Nucl Med Mol Imaging 38:899-910

22. Horger M, Eschmann SM, Pfannenberg C, Storek D, Dammann F, Vonthein R, Claussen CD, Bares R (2003) The value of SPET/ $\mathrm{CT}$ in chronic osteomyelitis. Eur $\mathrm{J}$ Nucl Med Mol Imaging 30:1665-1673

23. Graute V, Feist M, Lehner S, Haug A, Müller PE, Bartenstein P, Hacker M (2010) Detection of low-grade prosthetic joint infections using ${ }^{99 \mathrm{~m}}$ Tc-antigranulocyte SPECT/CT: initial clinical results. Eur J Nucl Med Mol Imaging 37:1751-1759

24. Meller J, Ivancevic V, Conrad M, Gratz S, Munz DL, Becker W (1998) Clinical value of immunoscintigraphy in patients with fever of unknown origin. J Nucl Med 39:1248-1253

25. Hubalewska A, Dudek D, Dubiel J, Płaczkiewicz-Jankowska E, Huszno B, Staszczak A, Frasik W (2004) Screening for acute myocarditis-is scintigraphy with ${ }^{99 \mathrm{~m}} \mathrm{Tc}$-anti-granulocyte BW 250/183 an answer? Nucl Med Rev Cent East Eur 7:165-169

26. Györke T, Duffek L, Bártfai K, Makó E, Karlinger K, Mester A, Tarján Z (2000) The role of nuclear medicine in inflammatory bowel disease. A review with experiences of aspecific bowel activity using immunoscintigraphy with ${ }^{99 \mathrm{~m}} \mathrm{Tc}$ anti-granulocyte antibodies. Eur J Radiol 35:183-192

27. Real R, Linhares P, Fernandes H, Rosas MJ, Gago MF, Pereira J, Vaz R (2011) Role of Tc-Sulesomab immunoscintigraphy in the management of infection following deep brain stimulation surgery. Neurol Res Int 2011:817951 
28. Rennen HJ, Boerman OC, Oyen WJ, van der Meer JW, Corstens FH (2001) Specific and rapid scintigraphic detection of infection with ${ }^{99 \mathrm{~m}}$ Tc-labeled interleukin-8. J Nucl Med 42:117-123

29. Bleeker-Rovers CP, Rennen HJ, Boerman OC, Wymenga AB, Visser EP, Bakker JH, van der Meer JW, Corstens FH, Oyen WJ (2007) ${ }^{99 \mathrm{~m}}$ Tc-labelled interleukin 8 for the scintigraphic detection of infection and inflammation: first clinical evaluation. J Nucl Med 48:337-343

30. Gratz S, Rennen HJ, Boerman OC, Oyen WJ, Burma P, Corstens FH (2001) ${ }^{99 \mathrm{~m}}$ Tc-interleukin-8 for imaging acute osteomyelitis. J Nucl Med 42:1257-1264

31. Signore A, Glaudemans AW (2011) The molecular imaging approach to image infections and inflammation by nuclear medicine techniques. Ann Nucl Med 25:681-700

32. Britton KE, Wareham DW, Das SS, Solanki KK, Amaral H, Bhatnagar A, Katamihardja AH, Malamitsi J, Moustafa HM, Soroa VE, Sundram FX, Padhy AK (2002) Imaging bacterial infection with ${ }^{99 \mathrm{~m}}$ Tc-ciprofloxacin (Infecton). J Clin Pathol $55: 817-823$

33. Sonmezoglu K, Sonmezoglu M, Halac M, Akgün I, Türkmen C, Onsel C, Kanmaz B, Solanki K, Britton KE, Uslu I (2001) Usefulness of ${ }^{99 \mathrm{~m}} \mathrm{Tc}$-ciprofloxacin (infecton) scan in diagnosis of chronic orthopedic infections: comparative study with ${ }^{99 \mathrm{~m}} \mathrm{Tc}$ HMPAO leukocyte scintigraphy. J Nucl Med 42:567-574

34. Gemmel F, De Winter F, Van Laere K, Vogelaers D, Uyttendaele D, Dierckx RA (2004) ${ }^{99 \mathrm{~m}} \mathrm{Tc}$ ciprofloxacin imaging for the diagnosis of infection in the postoperative spine. Nucl Med Commun 25:277-283

35. Sarda L, Crémieux AC, Lebellec Y, Meulemans A, Lebtahi R, Hayem G, Génin R, Delahaye N, Huten D, Le Guludec D (2003) Inability of ${ }^{99 \mathrm{~m}} \mathrm{Tc}$-ciprofloxacin scintigraphy to discriminate between septic and sterile osteoarticular diseases. J Nucl Med 44:920-926

36. Siaens RH, Rennen HJ, Boerman OC, Dierckx R, Slegers G (2004) Synthesis and comparison of ${ }^{99 \mathrm{~m}} \mathrm{Tc}$-enrofloxacin and ${ }^{99 \mathrm{~m}}$ Tc-ciprofloxacin. J Nucl Med 45:2088-2094

37. Lazzeri E, Pauwels EK, Erba PA, Volterrani D, Manca M, Bodei L, Trippi D, Bottoni A, Cristofani R, Consoli V, Palestro CJ, Mariani G (2004) Clinical feasibility of two-step streptavi$\mathrm{din} /{ }^{111}$ In-biotin scintigraphy in patients with suspected vertebral osteomyelitis. Eur J Nucl Med Mol Imaging 31:1505-1511

38. Lazzeri E, Erba P, Perri M, Doria R, Tascini C, Mariani G (2010) Clinical impact of SPECT/CT with In-111 biotin on the management of patients with suspected spine infection. Clin Nucl Med 35:12-17

39. Lupetti A, Pauwels EKJ, Nibbering PH, Welling MM (2003) ${ }^{99 \mathrm{~m}} \mathrm{Tc}$-antimicrobial peptides: promising candidates for infection imaging. Q J Nucl Med 47:238-245

40. Lupetti A, Welling MM, Mazzi U, Nibbering PH, Pauwels EK (2002) Technetium-99m labeled fluconazole and antimicrobial peptides for imaging of Candida albicans and Aspergillus fumigatus infections. Eur J Nucl Med Mol Imaging 29:674-679

41. Sarda-Mantel L, Saleh-Mghir A, Welling MM, Meulemans A, Vrigneaud JM, Raguin O, Hervatin F, Martet G, Chau F, Lebtahi R, Le Guludec D (2007) Evaluation of ${ }^{99 \mathrm{~m}}$ Tc-UBI $29-41$ scintigraphy for specific detection of experimental Staphylococcus aureus prosthetic joint infections. Eur J Nucl Med Mol Imaging 34:1302-1309

42. Meléndez-Alafort L, Rodríguez-Cortés J, Ferro-Flores G, Arteaga De Murphy C, Herrera-Rodríguez R, Mitsoura E, MartínezDuncker C (2004) Biokinetics of ${ }^{99 \mathrm{~m}}$ Tc-UBI 29-41 in humans. Nucl Med Biol 31:373-379

43. Sarda L, Saleh-Mghir A, Peker C, Meulemans A, Crémieux AC, Le Guludec D (2002) Evaluation of ${ }^{99 \mathrm{~m}}$ Tc-ciprofloxacin scintigraphy in a rabbit model of Staphylococcus aureus prosthetic joint infection. J Nucl Med 43:239-245
44. Akhtar MS, Qaisar A, Irfanullah J, Iqbal J, Khan B, Jehangir M, Nadeem MA, Khan MA, Afzal MS, Ul-Haq I, Imran MB (2005) Antimicrobial peptide ${ }^{99 \mathrm{~m}}$ Tc-ubiquicidin $29-41$ as human infection-imaging agent: clinical trial. J Nucl Med 46:567-573

45. Vallejo E, Martinez I, Tejero A, Hernandez S, Jimenez L, Bialostozky D, Sanchez G, Ilarraza H, Ferro-Flores G (2008) Clinical utility of ${ }^{99 \mathrm{~m}} \mathrm{Tc}$-labeled ubiquicidin $29-41$ antimicrobial peptide for the scintigraphic detection of mediastinitis after cardiac surgery. Arch Med Res 39:768-774

46. Ostovar A, Assadi M, Vahdat K, Nabipour I, Javadi H, Eftekhari M, Assadi M (2013) A pooled analysis of diagnostic value of ${ }^{99} \mathrm{~m}$ Tc-Ubiquicidin (UBI) scintigraphy in detection of an infectious process. Clin Nucl Med 38:413-416

47. Liberatore M, Pala A, Scaccianoce S, Anagnostou C, Di Tondo U, Calandri E, D'Elia P, Gross MD, Rubello D (2009) Microbial targeting of ${ }^{99 m}$ technetium-labelled-recombinant human betadefensin-3 in an animal model of infection: a feasibility pilot study. J Nucl Med 50:823-826

48. Jamar F, Buscombe J, Chiti A, Christian PE, Delbeke D, Donohoe KJ, Israel O, Martin-Comin J, Signore A (2013) EANM/ SNMMI guideline for ${ }^{18} \mathrm{~F}$-FDG use in inflammation and infection. J Nucl Med 54:647-658

49. Palestro CJ, Love C (2012) Decreased sensitivity of ${ }^{18}$ F-fluorodeoxyglucose imaging in infection and inflammation. Semin Nucl Med 42:261-266

50. Forstrom LA, Dunn WL, Mullan BP, Hung JC, Lowe VJ, Thorson LM (2002) Biodistribution and dosimetry of [F-18] fluorodeoxyglucose labelled leukocytes in normal human subjects. Nucl Med Commun 23:721-725

51. Dumarey N, Egrise D, Blocklet D, Stallenberg B, Remmelink M, del Marmol V, Van Simaeys G, Jacobs F, Goldman S (2006) Imaging infection with ${ }^{18}$ F-FDG-labeled leukocyte PET/CT: initial experience in 21 patients. J Nucl Med 47:625-632

52. Rini JN, Bhargava KK, Tronco GG, Singer C, Caprioli R, Marwin SE, Richardson HL, Nichols KJ, Pugliese PV, Palestro CJ (2006) PET with FDG-labeled leukocytes versus scintigraphy with ${ }^{111}$ In-oxine-labeled leukocytes for detection of infection. Radiology 238:978-987

53. Palestro CJ, Love C, Miller TT (2007) Diagnostic imaging tests and microbial infections. Cell Microbiol 9:2323-2333

54. Yilmaz S, Ocak M, Asa S, Aliyev A, Ozhan M, Halac M, Sager S, Kabasakal L, Sonmezoglu K (2012) The different distribution patterns of FDG and FDG-labelled WBC in inflammatory and infectious lesions. Eur J Nucl Med Mol Imaging 39:1660-1661

55. Yilmaz S, Asa S, Ozhan M, Halac M (2013) Graft infection imaging with FDG and FDG-labeled leukocytes. Intern Med 52:1009-1010

56. Bhargava KK, Gupta K, Nichols KJ, Palestro CJ (2009) In vitro human leukocyte labeling with ${ }^{64} \mathrm{Cu}$ : an intraindividual comparison with ${ }^{111}$ In-oxine and ${ }^{18}$ F-FDG. Nucl Med Biol 36:545-549

57. Di Bartolo N, Sargeson AM, Smith SV (2006) New ${ }^{64} \mathrm{Cu}$ PET imaging agents for personalised medicine and drug development using the hexa-aza cage, SarAr. Org Biomol Chem 4:3350-3357

58. Liu Y, Abendschein D, Woodard GE, Rossin R, McCommis K, Zheng J, Welch MJ, Woodard PK (2010) Molecular imaging of atherosclerotic plaque with ${ }^{64} \mathrm{Cu}$-labeled natriuretic peptide and PET. J Nucl Med 51:85-91

59. Dearling JL, Packard AB (2012) PET-radioimmunodetection of integrins: imaging acute colitis using a ${ }^{64} \mathrm{Cu}$-labeled anti- $\beta_{7}$ integrin antibody. Methods Mol Biol 757:487-496

60. Pala A, Liberatore M, D'Elia P, Nepi F, Megna V, Mastantuono M, Al-Nahhas A, Rubello D, Barteri M (2012) Labelling of granulocytes by phagocytic engulfment with ${ }^{64} \mathrm{Cu}$-labelled chitosan-coated magnetic nanoparticles. Mol Imaging Biol 14:593-598 
61. Sathekge M (2008) The potential role of ${ }^{68} \mathrm{Ga}$-labeled peptides in PET imaging of infection. Nucl Med Commun 29:663-665

62. Rizzello A, Di Pierro D, Lodi F, Trespidi S, Cicoria G, Pancaldi D, Nanni C, Marengo M, Marzola MC, Al-Nahhas A, Rubello D, Boschi S (2009) Synthesis and quality control of ${ }^{68} \mathrm{Ga}$ citrate for routine clinical PET. Nucl Med Commun 30:542-545

63. Nanni C, Errani C, Boriani L, Fantini L, Ambrosini V, Boschi S, Rubello D, Pettinato C, Mercuri M, Gasbarrini A, Fanti S (2010) ${ }^{68} \mathrm{Ga}$-citrate PET/CT for evaluating patients with infections of the bone: preliminary results. J Nucl Med 51:1932-1936

64. Kumar V, Boddeti DK, Evans SG, Roesch F, Howman-Giles R (2011) Potential use of ${ }^{68} \mathrm{Ga}$-apo-transferrin as a PET imaging agent for detecting Staphylococcus aureus infection. Nucl Med Biol 38:393-398

65. Petrik M, Haas H, Dobrozemsky G, Lass-Flörl C, Helbok A, Blatzer M, Dietrich H, Decristoforo C (2010) ${ }^{68}$ Ga-siderophores for PET imaging of invasive pulmonary aspergillosis: proof of principle. J Nucl Med 51:639-645

66. Petrik M, Franssen GM, Haas H, Laverman P, Hörtnagl C, Schrettl M, Helbok A, Lass-Flörl C, Decristoforo C (2012) Preclinical evaluation of two ${ }^{68} \mathrm{Ga}$-siderophores as potential radiopharmaceuticals for Aspergillus fumigatus infection imaging. Eur J Nucl Med Mol Imaging 39:1175-1183

67. Boerman OC, Laverman P, Oyen WJ (2012) FIAU: from reporter gene imaging to imaging of bacterial proliferation. Am $\mathrm{J}$ Nucl Med Mol Imaging 2:271-272
68. Bettegowda C, Foss CA, Cheong I, Wang Y, Diaz L, Agrawal N, Fox J, Dick J, Dang LH, Zhou S, Kinzler KW, Vogelstein B, Pomper MG (2005) Imaging bacterial infections with radiolabelled 1-(2'-deoxy-2' fluoro- $\beta$-D-arabinofurasonyl)-5-iodouracil. Proc Natl Acad Sci USA 102:1145-1150

69. Pullambhatla M, Tessier J, Beck G, Jedynak B, Wurthner JU, Pomper MG (2012) [125I]FIAU imaging in a preclinical model of lung infection: quantification of bacterial load. Am J Nucl Med Mol Imaging 2:260-270

70. Diaz LA Jr, Foss CA, Thornton K, Nimmagadda S, Endres CJ, Uzuner O, Seyler TM, Ulrich SD, Conway J, Bettegowda C, Agrawal N, Cheong I, Zhang X, Ladenson PW, Vogelstein BN, Mont MA, Zhou S, Kinzler KW, Vogelstein B, Pomper MG (2007) Imaging of musculoskeletal bacterial infections by $\left[{ }^{124}\right.$ I]FIAU-PET/CT. PLoS One 2:e1007

71. Conti F, Priori R, Chimenti MS, Coari G, Annovazzi A, Valesini G, Signore A (2005) Successful treatment with intraarticular infliximab for resistant knee monoarthritis in a patient with spondyloarthropathy - a role for scintigraphy with Tc-99 m-infliximab. Arthritis Rheum 52:1224-1226

72. Malviya G, Conti F, Chianelli M, Scopinaro F, Dierckx RA, Signore A (2010) Molecular imaging of rheumatoid arthritis by radiolabelled monoclonal antibodies: new imaging strategies to guide molecular therapies. Eur $\mathrm{J}$ Nucl Med Mol Imaging $37: 386-398$ 